China Perspectives

$2011 / 3$ | 2011

Chinese Medicine: The Global Influence of an Evolving Heritage

\title{
The Transmission and Practice of Chinese Medicine
} An Overview and Outlook

\section{Éric Marié}

Translator. Will Thornely

\section{(2) OpenEdition Journals}

Electronic version

URL: http://journals.openedition.org/chinaperspectives/5613

DOI: 10.4000/chinaperspectives.5613

ISSN: 1996-4617

Publisher

Centre d'étude français sur la Chine contemporaine

\section{Printed version}

Date of publication: 1 October 2011

Number of pages: 5-13

ISSN: 2070-3449

\section{Electronic reference}

Éric Marié, «The Transmission and Practice of Chinese Medicine », China Perspectives [Online] 2011/3 | 2011, Online since 30 September 2011, connection on 28 October 2019. URL : http:// journals.openedition.org/chinaperspectives/5613; DOI : 10.4000/chinaperspectives.5613 


\title{
The Transmission and Practice of
}

\section{Chinese Medicine}

\author{
An Overview and Outlook
}

\author{
ÉRIC MARIÉ*
}

\begin{abstract}
Chinese medicine is a medical system that was developed in China over a long period of time and has subsequently spread over the rest of the world, especially over recent decades. This study aims first to identify this medicine and to examine the changes that accompanied its institutionalisation in the People's Republic of China starting in the 1950's, then to set out the continuities and breaking points that have characterised the ways in which it is transmitted, from traditional apprenticeship training to the development of national university syllabuses. It then looks into the way in which Chinese medicine has faced up to biomedicine and sets out a comparative analysis of the paradigms of these two systems, before describing the way in which this exotic medicine has been received and adapted in the West. This makes it possible to grasp the difficulties and issues involved in its globalisation and the increasingly pressing need, from the perspective of university teaching and research, for a more complete, objective and pragmatic approach to studying it.
\end{abstract}

KEYWORDS: Chinese medicine, history of medicine, transmission, university, medical systems comparison.

\section{The identity, specificity and status of Chinese medicine in China}

${ }^{2}$ hinese medicine is made up of a set of theories and practices developed in China over a long period of time, the oldest sources having been written more than two thousand years ago. It spread initially over the whole of East Asia, and more recently to the West. Backed up by a vast literary corpus and resting on its own paradigmatic construction, it gradually established itself as a genuine medical system including, in particular, its own representation of the body and universe, distinctive conceptions of physiology, aetiology, and pathology, and a therapeutic arsenal, nosography, and diagnostic methods of a complex and elaborate nature. ${ }^{(1)}$ It should also be noted that it presents two specific features that set it apart from both a historical and anthropological point of view. The first is the remarkable epistemological continuity of its theoretical foundations, which has been maintained for centuries, at least until the recent past. Admittedly, there have been additions and amendments, but it has certainly not been subject to such fundamental transformations as the scientific revolutions that have marked the history of Western medicine since the beginning of the nineteenth century. The second unique feature of the Chinese medicine system is that it not only continues to be practised and recognised at an institutional level in China and a number of other Asian countries, but has also been adopted, either in its entirety or partially, in a number of countries that are both geographically and culturally far removed from China. The exportable aspect of Chinese medicine means it has a number of points in common with contemporary Western medicine, although for different reasons and in different proportions that are interesting to note. The identity of this medical system, and the way it spreads and adapts to different public health systems, constitute a study model and pose a number of questions that come under disciplines as diverse as history, anthropology, economics, politics, and health law. The aim of this article is to look into several aspects of the issues raised by its spread and its practice, both in China and in the West, including through its relationship with Western medicine.

The specific identity of Chinese medicine is a complex question in itself. Should all medicines practised in China be labelled as such? Even if we set aside contemporary biomedicine, which is now commonly practised in China as in all industrialised countries, and is basically applied there in much the same way as in the West, it is necessary to distinguish between several traditional systems used in China. On the one hand, there are "unofficial" popular healing practices based on divination (算命 - suanming), witchcraft (巫術 - wushu), and religious beliefs (prayers, rites, and spiritual exercises). These disparate practices can be likened to others that continue to exist in all societies. Of the "official" traditional medicine systems in China, i.e., systems supported by a hospital infrastructure and state-controlled education, it is still necessary to make the distinction between

Éric Marié has dedicated himself to the study of Chinese medicine for more than 30 years. He has received both traditional apprenticeship training with a master and a university education in the discipline, mainly at the Faculty of Chinese Medicine in Jiangxi, where he was appointed professor (1992), before being made director of a research unit (1998). Since completing his studies in Paris with a PhD from EHESS (School for Advanced Studies in the Social Sciences) in 2003, he has taught various aspects of Chinese medicine in the Universities of Geneva, Lausanne, and Louvain-la-Neuve. He is currently course director for the new university qualifications in Chinese medicine at the Faculty of Medicine in the University of Montpellier.

1. Many publications offer an introduction to the theories and diagnostic and treatment methods of Chinese medicine, including: C. Maciocia, The foundations of Chinese medicine, Elsevier, 2005 (2nd edition); Éric Marié, Précis de médecine chinoise, Escalquens, Dangles, 2008 (new edition, revised, corrected, and enlarged). 
those connected with the non-Han minorities that are established in various ways on the political landscape today and can be qualified as ethnic (民族醫學 - minzu yixue), (2) and Chinese medicine (中醫 - zhongyi) in the strict sense of the term.

It should be noted that zhongyi is a contemporary term and refers indiscriminately to learned medicine that was developed over the whole course of the Imperial period as well as to contemporary Chinese medicine, which today has official status, and not to Western medicine (西醫 - xiyi). When they started to translate manuals into English in the 1950s, the Chinese decided to translate zhongyi as "Traditional Chinese Medicine," the obvious intention being, according to Volker Scheid, (3) to generate a certain perception of Chinese medicine in the West. This term soon became widespread and was used as the model when translating zhongyi into other Western languages, (4) but it paradoxically gave rise to two contradictory conceptions: some people associated with it the idea of it transcending its origins and being passed on in seamless fashion, whereas others saw the term more as a breaking point between an ancient, imperial medicine and another, modern medicine influenced by Communist materialism and forever cut from its roots.

Finally, the term "traditional medicine" refers to conceptions that have been criticised by Paul Unschuld, (5) who points to the influence of work by Erwin Ackerknecht in medical anthropology, ${ }^{(6)}$ which saw the approach whereby medicine is viewed as a cultural system becoming widespread. Yet Chinese medicine cannot be compared to an ethnomedicine, either in terms of its history or in the way it has spread over the world. (7) It has more in common with the learned medicines category, insofar as its specific nature is mainly defined by a body of founding texts that have been quoted extensively throughout history and give it a complex theoretical structure. ${ }^{\left({ }^{8}\right)}$ This written corpus is particularly voluminous: the Zhongguo yiji tongkao (中國醫籍通考 - Comprehensive Study of Chinese Medical Texts), (9) a bibliographical work of nearly 6,000 pages in four volumes, lists more than 9,000 works produced over a period spanning more than 2,000 years. The importance of these sources is recognised by some contemporary Chinese researchers, for example Liu Lihong, ${ }^{(10)}$ who prefers the translation "Classical Chinese Medicine" when talking about the discipline he practises and teaches, rather than "Traditional Chinese Medicine," which he considers misleading and ambiguous.

However, above and beyond the simple issue of terminology, it is the question of preserving the authenticity of knowledge and practices and the continuity of the essence of Chinese medicine that has become a cause for concern. In order to understand this concern, it is necessary to analyse the factors that have enabled this medical system to endure and develop over the long term, while keeping a remarkable level of epistemological continuity. This was made possible for centuries by the transmission of knowledge via a whole range of filiations, lineages, and classical schools that, despite occasional disagreement on certain specific points, demonstrated complementarity and overall paradigmatic consistency because they were based on the same founding texts and the theoretical construction stemming from them. Although medicine was not a truly organised profession - the careers of individual doctors would vary, and practice methods could differ greatly - these "currents of tradition" provided the basis and the central theme when it came to transmitting knowledge. (11) However, the exceptional longevity of Chinese medicine comes down to another factor: the political and social organisation and the cultural framework remained relatively stable for more than 2,000 years under the Imperial regime. Nei- ther changes in dynasty nor the challenges of foreign doctrines were able to undermine the continuity of this medical system in any lasting manner until the start of the twentieth century.

It was not until the 1920s that there was a break with the past, and this took place for three reasons. First of all, the brutal political changes that took place in China and the resulting social disorganisation between 1911 and 1949, and to a certain extent, the influence the Cultural Revolution subsequently had on intellectual creation, created a climate that did not favour the continuity of a traditional system. Furthermore, the challenge posed by the mass intrusion of Western medicine weakened Chinese medicine, whose status shifted from that of dominant to dominated medicine. There were even aborted attempts to completely eradicate its practice. For example, measures taken by the Kuomintang government in 1929 aimed to limit and even forbid the teaching, control the publication, and limit the practice of Chinese medicine. (12) Finally, it must not be forgotten that Chinese medicine was too slow to adopt the technological tools that enabled Western medicine to make the leap forward that distinguished its progress during the twentieth century. It did not modernise its terminology or even, at the very least, make its dialectics more accessible while preserving its intellectual rigour, nor did it develop an investigation and research methodology that would have enabled it to meet the usual scientific criteria. Several reasons may be advanced to explain these difficulties, notably the great complexity of its theories, the diversity and sometimes disagreements between the schools, and the independence of its epistemological construction. While contemporary Western medicine was only able to develop by drawing from other basic sciences such as biology, chemistry, and physics, Chinese medicine was, in a way, a victim of its own completeness, which made assimilation difficult. The result of this was devastating: Chinese medicine was reduced to the status of pre-scientific knowledge of which only the esoteric facet was visible.

At the start of Communism, Chinese medicine was alternately rejected and supported by the regime. ${ }^{(13)}$ Without going into detail about the par-

2. This category is, in itself, subject to debate. For example, as far as the government of the People's Republic of China is concerned, Tibetan medicine has, since the annexation of Tibet, been the medicine of a non-Han Chinese minority in practice.

3. Volker Scheid, Chinese Medicine in Contemporary China, Durham and London, Duke University Press, 2002, p. 3.

4. In English, the expression "Traditional Chinese Medicine" or TCM is commonly used, an in French "Médecine traditionnelle chinoise" or MTC.

5. Paul U. Unschuld, Medicine in China, a History of Ideas, Berkeley-Los Angeles-London, University of California Press, 1985, p. 3.

6. Erwin H.Ackerknecht, "Primitive Medicine and Culture Pattern," Bulletin of the History of the Medicine, no. 12 , pp. 545-574.

7. A further related question that I will not cover in depth here, because I have already discussed it in another publication, is that of the unity or plurality of Chinese medicine (or medicines). Cf. Éric Marié, "La médecine chinoise: mutations et enjeux d'un système médical traditionnel confronté à la modernité," Monde chinois, no. 5, 2005, p. 103

8. Given the pre-eminence of the written corpus and the theoretical complexity of experimentation, Chinese medicine can absolutely not be described as an empirical medicine.

9. Zhongguo yiji tongkao, Shanghai, Shanghai zhongyi xueyuan chuban she, 1992.

10. Concerning Liu Lihong and his opinion about the importance of the classical texts, see the article by Pierre-Henry de Bruyn and Evelyne Micollier in this special issue.

11. An excellent illustration of the importance of the medical lineages is provided in a work that retraces the history of one of them over the course of four centuries: Volker Scheid, Current of Tradition in Chinese Medicine, 1626-2006, Seattle, Eastland Press, 2007

12. The reaction of the public and associations resulted in a major gathering in Shanghai on 17 March 1929. A petition addressed to the government by 132 associations united in congress resulted in the repeal of measures that had been taken against Chinese medicine. 17 March became the traditional medicine day.

13. For more information on the historical details, refer to: Volker Scheid, Chinese Medicine in contemporary China, op. cit. 
adoxical standpoints expressed over the course of the 1950s, it is worth pointing out that, on the one hand, it was discredited as "feudal society's feudal medicine" (封建社會封建醫 - fengjian shehui fengjian yi), something that needed to be reformed, ideologically reconditioned, and placed under the control of Western scientific medicine. On the other hand, it was viewed as a precious treasure (寶庫 - baoku) that needed to be preserved - especially in a context in which all local resources had to be mobilised by limiting the use of foreign technologies and medication and in order to control the "undesirable ideological tendencies of practitioners trained in Western medicine." (14) Doctors of Chinese medicine were considered to be more malleable at this time because of the precarious nature of their status. The relationship between Chinese medicine and Western medicine was also unstable over the same period. Sometimes, traditional doctors were required to learn Western medicine; at other times, practitioners of Western medicine had to study Chinese medicine. In the end, it became clear that it would be necessary to allow and support the existence of two medical systems and to encourage them to develop closer ties. Therefore, in 1956, the first institutes of Chinese medicine (中醫學院 - zhongyi xueyuan) were opened in Beijing, Shanghai, Guangzhou, and Chengdu and, over the years that followed, in each of the provinces.

\section{The teaching of Chinese medicine in China: Traditional transmission and institutional structures}

The teaching of Chinese medicine had to be institutionalised in order for it to be standardised on a national scale. Given the lack of a university model specific to Chinese medicine, the model used by Western medicine was used as a basis for its organisation and teaching methods, although the content was approved by experts in Chinese medicine.

Over the course of history, the variety of forms in which Chinese medicine has been taught in China has been as diverse as the ways in which it has been practised, and it is not easy to grasp all of the aspects because most of the writings that have come to us were written by men of letters, and hardly reflect the state of the more popular practices other than by making the odd, often derogatory, allusion in the form of scornful comparisons or examples of illnesses made worse by apparently incompetent practitioners. On the other hand, medicine was not a clearly defined profession, especially before the Mongol invasion in the thirteenth century, after which it started to be seen as an acceptable career for an intellectual. Just as there were fundamental differences between the work of the Emperor's doctor and the itinerant healer or a practitioner born into a family line of doctors, the learning path and methods of transmitting knowledge varied greatly, and some are difficult to appraise due to a lack of sources. Some doctors started their training during childhood, while others - including some of the most prestigious recorded in history - began their studies on the back of various sets of circumstances, for example failing an exam that dashed their hopes of taking up a career in the civil service or as the result of an illness that afflicted them or a member of their family. ${ }^{(15)}$ It is important to remember that up until the nineteenth century, medicine could either be one's main occupation or a sideline activity, as described in the biography of Ling Xusheng (凌地升), a man of letters who completed his studies in 1801 and became sub-prefect of Shandong: "He excelled in medicine, and when an epidemic broke out in the population, he travelled around the sub-prefecture to examine [the sick]." (16) Finally,

some of the writers of medical treatises and commentaries were selftaught in medicine, and had, to all intents and purposes, completed no practical training or clinical professional activity.

If we take the case of practitioners who were fully dedicated to practising the art of medicine, until the start of the twentieth century their training consisted mainly of learning transmitted from master to disciple, often in the home. The student would be trained by his father, an uncle or a person to whom he had been introduced through an informal network. Such was the case of Yao Hesheng (姚荷生 1911-1998), a celebrated doctor in Jiangxi Province who became the first president of Jiangxi Institute of Chinese Medicine (江西中醫學院 - Jiangxi zhongyi xueyuan). I met him during my studies in China and spent a lot of time with his closest disciples. Even though he came from a long line of doctors, he did not consider embarking on a medical career until the age of 18 , when he discovered the admiration and gratitude patients felt for his uncle, Yao Guimei. Sufficiently moved, he decided to follow the route of Chinese medicine under his uncle's instruction. His apprenticeship is quite revealing of what was being practised prior to the 1950s. He first studied the classical texts, in particular the Huangdi neijing (黃帝內經 - The Yellow Emperor's Inner Classic), the Nanjing (難經 - The Classics of Difficulties), the Shang Han Lun (傷寒論 - Treatise on Febrile Diseases) and the Jingui yaolue fanglun (金匱要略方論 - Essentials and Discussions of Prescriptions in the Gold Casket). For the Shang Han Lun, he also followed the teachings of a friend of his uncle, Xie Shanghu, who had an excellent knowledge of this work and the corpus stemming from it. Two years later, he started practising under the supervision of his masters, and continued this apprenticeship for several years.

14. Ibid., p. 70 .

15. Zhang Zhongjing (150-219), who is without a doubt the most unanimously respected doctor and the one whose work has been studied and quoted the most in every era, told of how the deaths of many of his close relations from complications relating to shanghan 傷寒 (literally "cold damage," referring to a group of pathologies in ancient Chinese nosology) was behind his desire to find therapeutic solutions to these illnesses.

16. Guangzhou fuzhi, 1880, 130, liezhuan 19, cited in Florence Bretelle Establet, La santé en Chine du Sud (1898-1928), Paris, CNRS Editions, 2002, pp. 78-79. 
Yao Hesheng's case illustrates several recurring aspects of the traditional methods of transmission. Everything started with the intensive study of the most fundamental classical works, with variations depending on the school or line. The student would not be allowed to learn from several different masters, especially if they were not from the same school. However, he would be integrated into a network, and his mentor could direct him to another specialist to add to his knowledge, if necessary. In order to understand the texts, the first task was to memorise them. This method may seem demanding, but it subsequently made it possible to receive and very quickly take in explanations because, with the text by now forged into the mind, there was no need to refer back to notes in an inevitably time-consuming fashion. The importance of taking in knowledge in this way is best illustrated by the following anecdote. During the 1930s, several masters, including Yao Hesheng's, decided to compile their joint experiences in the area of diagnostics. Together, they wrote a book about the subject, but instead of having it printed, they had eight copies made, this being the total number of main disciples under them. They then gave one copy to each disciple for 30 days, with the mission of learning it by heart. When this time was up, they took back the copies and destroyed them. This may seem a surprising thing to do, but from the perspective of these Chinese doctors, it was essential to always have the knowledge they would need to treat their patients in their mind, without relying on notes. To this day, a traditional Chinese doctor will practically never consult a manual during a consultation because to do so will, more likely than not, cause patients to become distrustful and feel the doctor lacks sufficient mastery of the knowledge.

Although the institutionalisation of Chinese medicine has given it an official status and a certain level of social recognition, it has also, in encouraging the professionalization of the discipline, clearly turned the traditional ways of transmitting knowledge upside down. Standardisation has given students mobility, because they can start their learning in one university and continue it in another. However, this statement does need to be qualified, because the various institutes have kept a small amount of independence in terms of how the syllabuses are organised, meaning each faculty is able to retain a degree of local specificity. For example, the teaching of Chinese medicine in Shanghai places greater emphasis on the Westernised scientific approach, while in Guangzhou tradition carries more weight. It is therefore possible to plot a kind of map of Chinese medicine teaching, with all its subtleties and developments, because these trends undergo variations over time depending on changes in the teaching staff and local policies, both inside and outside the university system. Be that as it may, mass education and the increasingly marked subjection of the discipline to Western medicine have had undeniable consequences. Several factors come into play and help us to understand this transformation.

The first is linked to the journeys made by students over the course of their training. Ever since reforms began to be introduced in the teaching of Chinese medicine at the end of the 1950s, three types of institutions have been responsible for training future practitioners. Schools of Chinese medicine (中醫學校 - zhongyi xuexiao) offer short or intermediate level courses that usually last three years. They are not, strictly speaking, at the same level as university studies. Institutes of Chinese medicine (中醫學院 - zhongyi xueyuan) and universities of Chinese medicine and pharmacy (中醫藥大學 - zhongyi yao daxue) train students to xueshi (學士) level, which corresponds to five years of training. Then, after a competitive examination and three additional years concluded by an exam and sup- ported by a research project in a specialist area, they reach shuoshi (碩士) level, and following another competitive examination, three more years of study, and a second thesis, they reach boshi (博士 $)^{(17)}$ level after a total of 11 years of university studies. This course is identical, both in duration and requirements, to the corresponding course in Western medicine, but the subject matter is obviously different. There are several types of courses: Chinese medicine, pharmacy, acupuncture/moxibustion, and functional reeducation. In Chinese medicine, when students are studying for the xueshi, the education they receive consists of approximately 3,800 hours of classes over the first four years. The final year is spent gaining full-time practical experience in a hospital. (18) Around 950 hours are given over to general subjects (foreign languages, basic sciences, history of the Communist Party, etc.). The rest is split between Chinese medicine (around 70 percent) and biomedicine (around 30 percent). Of the 2,000 or so hours spent learning Chinese medicine, 468 hours are given over to the teaching of the classical texts, which are made up of four fundamental corpus (Neijing, Shang Han Lun, Jingui yaolüe and Wenbing 溫病). In addition to these, other ancient theories and treatises that can be grouped together under the term gejia xueshuo (各家學説 - study of various schools) are studied. Knowledge of classical Chinese medicine (醫古文 - yiguwen) is considered necessary in order to be able to read the ancient texts, and 142 hours are dedicated to this discipline. The rest of the time is divided between the teaching of fundamental theories, diagnosis, acupuncture/moxibustion, materia medica of drugs, pharmacopoeia formulae, and clinical specialities (internal medicine, gynaecology, paediatrics, etc.).

A doctor trained in one or other of the medical traditions can legally and theoretically practise whichever of the two medicines he judges best suited to each patient, and can seek employment in a hospital or clinic of Chinese or Western medicine. However, this parallelism is distorted by the fact that although doctors in traditional medicine have fairly considerable training in Western medicine, the opposite cannot be said of doctors who have graduated from biomedicine faculties, who know next to nothing of Chinese medicine. Furthermore, in order to attend university, students must sit an examination for entry into higher education (高等院校入學考 試 - gaodeng yuanxiao ruxue kaoshi, shortened to gaokao - 高考). This is taken at the end of their secondary education, and the better their results, the wider the range of choices open to them. The relative devaluation of studies in Chinese medicine, which offers more limited career choices than Western medicine, notably on an international level, has a number of consequences. Firstly, the students recruited are not as intelligent. Secondly, not all of them feel the call of Chinese medicine, or even medicine in general; some would prefer to study business, for example, but have not achieved the grade required to fulfil this ambition. Finally, as a result of the links that exist between Chinese medicine and Western medicine, some students start off studying a Chinese medicine course only to switch to Western medicine later, at the shuoshi or boshi level. This phenomenon creates motivational disparity that does little to encourage competition. It cannot be denied that the method of recruitment, which is based on general disciplines taught during secondary education, poses a problem whichever way it is looked at. In South Korea, for example, the situation is

17. I have deliberately not translated the three levels to avoid confusion, because their equivalents in the UK involve different course durations.

18. The university syllabuses of Chinese medicine have changed a lot since 1956. The information below corresponds to practices that have been in place since the beginning of the 1990s, bearing in mind that there are minor variations from institute to institute. 
the opposite: the standard of the Oriental medicine ${ }^{(19)}$ faculties is higher there than in faculties of Western medicine because only the brightest students studying science subjects at secondary level are accepted into them. Therefore, even though the content of the studies does not necessarily appeal to them, many students aspire to follow this course because a degree in this subject opens up career possibilities comparable to those of prestigious universities in a Western country. For many, studying traditional medicine represents no more than a necessary procedure, and they complete it without enthusiasm. In short, the system of selecting candidates places excessive emphasis on the scientific disciplines (20) (mathematics, physics, chemistry, etc.), which are of little basic use when it comes to training a good doctor. The humanities, meanwhile, are neglected. This results in the recruitment of students who are not intellectually predisposed to assimilate this medical system, because Chinese medicine is based both on a wide general knowledge (history, philology, (21) etc.) and on a philosophy that calls not only for intellectual qualities but also for personal sensitivity in order to be able to grasp the deeper meaning.

Since the 1950s, many Chinese doctors have become aware of these problems. The drastic reforms implemented in the way education was organised soon met with resistance. On 16 July 1962, the graduation date of the first practitioners trained in the recently created institutes, five Chinese doctors ( Qin Bowei 秦伯未, Ren Yingqiu 任應秋, Li Chongren 李重人, Chen Shenwu 陳慎吾, and Yu Daoji 于道濟) wrote a letter of protest to the Ministry of Health. In it, they declared that the modernisation of teaching broke with the continuity of Chinese medicine as a living tradition, and suggested that a more marked emphasis be placed on the classical sources, as well as a return to traditional teaching methods. ${ }^{(22)}$ In response to this initiative, there was an increase in the share of the syllabuses that was assigned strictly to Chinese medicine, but the general organisation of teaching was not modified until 1977, after the Cultural Revolution, giving the discipline increased independence.

While it is undeniable that Chinese medicine has been shaken over the course of the last 60 years, these historical changes, considered a tragedy by some, must nevertheless be analysed in a more balanced manner. Long before the arrival of Communism, the situation in which the discipline found itself raised a number of problems. The professional organisation was not sufficient, the rivalry between schools hindered development and communication, and archaisms remained that would, in any case, have resulted in a crisis situation. It is impossible to say for certain that without a reform carried out by the government, Chinese medicine would have been able to survive and develop positively. With the benefit of hindsight, it is easy to point out everything that could have been avoided or improved in terms of preserving its heritage and modernising it. Yet it should also not be forgotten that even societies that did not experience the succession of political, economic, and social upheavals that took place in China from the time of the Unequal Treaties up to the end of the Cultural Revolution, have nevertheless lost whole swathes of their traditional knowledge, in some cases doing absolutely nothing to preserve it. While maintaining a critical standpoint and taking the problems set out above into account, it is also possible to examine the efforts that were made to enable Chinese medicine to develop. Even though certain initiatives were clumsy or motivated by questionable political interests, the effects they produced did sometimes serve to protect aspects of the Chinese medical tradition that could very easily have disappeared. They concern, among other things, access to ancient written sources and certain teaching methods.
For example, it is unfortunate that the study manuals for the great classics (Neijing, Shang Han Lun, etc.) that are used by university teaching programmes are simplified and only cover parts of the texts, rather than the whole works. This is a recurring criticism that can, at an absolute level, be justified. However, it also needs to be qualified for two main reasons. These manuals have made it possible for many students to learn about the structure and content of the classics. It would have been difficult for the vast majority of them to understand all of these works in their entirety. What is more, the considerable amount of work that has gone into editing over the course of several decades has made it possible to put a number of ancient medical works onto the market at reasonable prices, either in facsimile format or as typographical reprints of the first editions. The libraries of Chinese medicine institutes have therefore made them available to teachers and students, who can consult them in addition to the basic manuals. Can the complete works of Hippocrates, Galen, or Avicenna, or any other ancient medical treatise be accessed and consulted so easily in any Western country?

As far as the current methods of transmitting Chinese medical knowledge are concerned, although the traditional master-disciple relationship is no longer widespread, it has not totally disappeared. Therefore, a teacher can have students (學生 - xuesheng) and disciples (徒弟 - tudi). Some, for example the youngest university teachers (assistants and assistant lecturers, in particular), often only have students. Conversely, some doctors practising outside an institutional structure may have only disciples. However, the "venerable Chinese doctors" (老中醫 - laozhongyi) (23) practising in a hospital or university can have both disciples and students. It is not easy for one and the same person to hold both statuses at the same time, but it is possible to be a student for a few years before subsequently becoming a disciple to a master, or vice versa. The methods of learning are totally different to one another. A student follows a common syllabus, sits exams, obtains qualifications, and may himself become a teacher. The impact of the teaching on his personal life and the requirements in terms of behaviour go no further than following the general regulations that apply to the university. A disciple follows his master on a daily basis, spends time at his home or with his family, and travels with him if need be. His learning is based more than anything else upon observing, memorising, repeating gestures, and learning the specific techniques and even the secrets of his master. Some of his time is spent copying down the prescriptions of his instructor and following how he prepares remedies, even to the point of gathering the ingredients from the wild. More often than not, such proximity helps forge a very strong connection. The master has a moral authority that extends above and beyond the simple transfer of knowledge and includes instilling the disciple with the moral virtues of medicine (醫德 - yide).

19. The term "Oriental medicine" is used in South Korea to refer to a medical system whose sources and principles are close to those of Chinese medicine but which has its own specificities. In South Korea, as in China, traditional medicine enjoys a protected status. For more information on Korean medicine, see the article by Kang YeonSeok in this special issue.

20. On this subject, see Elisabeth Hsu, The transmission of Chinese Medicine, Cambridge, Cambridge University Press, 1999, pp. 145 sq.

21. The most important sources (founding texts, specific treatises, commentaries, etc.) are written in ancient Chinese script (古文 - guwen). The fundamental concepts are better served by a knowledge of the history of China and its philosophical doctrines than by an ability to solve differential equations.

22. Volker Scheid, Chinese Medicine in contemporary China, op. cit., p. 75.

23. The term lao (old) not only refers to age, but also carries with it an honorary connotation, the concept of "venerable." Therefore, simply being very old is not sufficient to be considered a laozhongyi, nor is it an indispensable characteristic, even though the title is not usually awarded to practitioners under 40 years of age. 
Although these forms of transmission have not always been looked upon favourably by the government authorities, they did finally authorise and even regulate them. Therefore, in 1958, under the authority of the Ministry of Health, 104 young practitioners were placed in the hands of 31 famous venerable Chinese doctors (名老中醫 - ming laozhongyi), who were required to receive them as disciples and teach them. ${ }^{(24)}$ The stated intention was to gather knowledge that was considered precious in order to then make it more available to future generations. Of course, questions might be asked about the value of a master/disciple link that is based on a government decision rather than a matter of personal choice, but it does show that this method of teaching was not rejected at a time when universities and national institutes of Chinese medicine were being opened. Similarly, years later, in June 1990, the Ministry of Health, the State Administration of Traditional Chinese Medicine and Pharmacy, and the Ministry of Employment joined forces to draw up a programme by which 500 famous venerable doctors would be invited to train and supervise a group of qualified doctors under a traditional form of teaching. On 20 October 1990, 725 disciples were chosen by selection and allocated to 462 masters. ${ }^{(25)}$ Finally, it should be noted that on 19 June 2009, an official list of 30 "national masters of Chinese medicine" (國醫大師 - guo yidashi) was published by the Chinese government at the joint instigation of three central departments: The Ministry of Human Resources and Social Security (人力 資源和社會保障部 - renli zeyuan he shehui baozhang bu), the Ministry of Health (衛生部 - weisheng bu) and the National Bureau of Chinese Medicine and Pharmacy (國家中醫藥管理局 - guojia zhongyiyao guanliju). The spirit of this list is, however, different to that of the laozhongyi, insofar as in this case it is an honorary distinction, the aim of which is to recognise, at the highest level, the contribution of key personalities who have marked the development of Chinese medicine, and who constitute a model for future generations. No teaching duties are explicitly associated with this title, which is more a recognition of the culmination of a career; all of those named on the list were born between 1916 and 1935. Starting to practise at a young age and continuing uninterrupted to an advanced age, well beyond the usual retirement time, is an implicit condition, because the selection criteria are as follows:

- A major contribution to the promotion of the discipline;

- Extraordinary academic and professional success in a national institution;

- A commitment to medicine or pharmacopoeia spanning more than 55 years and a reputation for high moral virtue.

The list is to be renewed every five years. Although no other criteria are officially stated, it should be noted that the selection was made in such a way as to strike a balance between the various specialist areas of Chinese medicine, the various institutions (there is only one doctor on the list per institution), and the various provinces of China. ${ }^{(26)}$ All of the names on the list have a profile that is very much oriented towards the classical tradition of Chinese medicine. This recognition can also be seen as a more general process of appreciating one's heritage, in a similar way to UNESCO's recognition of acupuncture and moxibustion in November 2010. (27) However, what it really brought to the fore in this case, through the legendary figures of contemporary Chinese medicine, is the existence of a heritage of "living national treasures." (28) It also seems that this selection is intended to act as a reminder that the government is mindful of the more traditional aspects of Chinese medi- cine, and that there is no relationship of subordination with Western medicine.

It must be acknowledged that although Chinese medicine and biomedicine coexist and, in theory, receive equal treatment from the government authorities, this does not mean to say that there are no tensions. It has been necessary to manage this coexistence from the very first days of the organisation of teaching by the universities. This resulted in the emergence of a specialist area, which is the synthesis of the two medical systems, the "combination of Chinese medicine and Western medicine" (中西醫結合 zhongxiyi jiehe), and became an official professional career that can be embarked upon after completing a basic course in one or other of the medicines. Even though the Ministry of Health did not use this term until $1980^{(29)}$ in the extension of the "Eleventh National Health Conference" (1979) during which Lü Bingkui (呂炳奎) announced the slogan: "Chinese medicine, Western medicine, and the combination of Chinese medicine and Western medicine are three great forces that will develop and coexist for a long time" (中醫, 西醫, 中西醫結合, 三支力量都要發展, 長期並存 Zhongyi, xiyi, zhongxiyi jiehe sanzhi liliang dou yao fazhan changqi bingcun), the idea of bringing together the two medical systems goes back much further. As early as the end of the nineteenth century, when foreign doctors came to establish themselves in China and brought Western medicine with them, a certain number of practitioners realised that it was no longer a question of ignoring Western medicine and that partial assimilation was becoming possible, and even necessary. However, this transition required decoding work, conceptual translations, and practical adaptations to be carried out. This work was performed by representatives of a new school of thought, the School of Sino-Western Convergence and Intercourse, (中西會通派 - Zhongxi huitong pai), of which Tang Zonghai (唐宗 海 1846-1897) was the forefather. ${ }^{(30)}$ First of all, learned doctors revisited the ancient theories and the application of traditional pharmaceutical substances in the light of contemporary science. For example, in a treatise (31) published for the first time in 1909, Zhang Xichun (張錫純 1860-1933) set out the links between certain kinds of cerebral haemorrhage and Internal Wind (內風 - neifeng), using classical formulae to "calm the Wind" for these pathologies. (32) Later on, and in the same vein, Ye Juquan (葉橘泉 1896-1989) transposed the action of Chinese pharmacopoeia formulae over to Western therapeutic criteria, after analysing the clinical pictures to which they correspond in classical medical literature. In this way, the signs and symptoms for which a "Minor Decoction of Bupleurum" (小柴胡湯 xiao chaihu tang) (33) - a formula consisting of seven drugs and found in

24. Volker Scheid, Chinese Medicine in contemporary China, op. cit., p. 169.

25. Ibid., p. 171

26. The complete list of doctors named as national masters of Chinese medicine, including the profile of each one, can be seen at www.zhongyiyao.net/tcm/doctor/5A5254AB2D76.html (consulted on 24 November 2011).

27. See the article by Frédéric Obringer in this special issue.

28. This term is borrowed from the Japanese model, which awards this informal title to masters of traditional disciplines, often in the fields of art or craftsmanship, whose knowledge and experience form part of the national cultural heritage that they are responsible for passing on.

29. Volker Scheid, Chinese Medicine in contemporary China, op. cit., p. 82.

30. For further information, see Zhen Zhiya, Fu Weikang, et al., Zhongguo yixue shi 中國醫學史 (A History of Medicine in China), Taipei, Zhiyin chubanshe, 2003, pp. 206-213.

31. Zhang Xichun, Yixuezhong zhongcanxi lu (Records of heart-felt experiences in medicine with references to the West), Hebei renmin chubanshe, 1957.

32. For an explanation of the physiopathological mechanisms of the "Internal wind" clinical picture, see Éric Marié, Précis de médecine chinoise, op. cit., p. 238.

33. For an analysis of the composition, actions and indications of this formula, see Éric Marié, Grand formulaire de pharmacopée chinoise, Vitré, Éditions Paracelse, 1991, pp. 441-442. 
Shang Han Lun, and whose clinical usage covers many areas of pathology - might be prescribed led him to conclude that the properties of this ancient prescription could be classified under what is termed, in the twentieth century, an anti-inflammatory action (消炎 - xiaoyan). The coming together of these two medical systems therefore showed itself, notably, through the revision and extension of nosography, by an openness towards another therapeutic approach, and by attempts to compare their fundamental paradigms. Pharmaceutical research into Chinese drugs started to be organised in the 1920s by researchers such as Chen Kehui, C.F. Schmidt, and B.E. Read, (34) who worked on Angelica sinica (當歸 - danggui) and Ephedra sinensis (麻黃 - mahuang). ${ }^{(35)}$

During the reconstruction of Chinese medicine that took place when it was institutionalised, the question of promoting a system that would link it with Western medicine was reopened, giving rise to questions and debates around the forms of this mixed discipline, which took on a number of names, for example combination (結合 - jiehe), unification (團結 - tuanjie), cooperation (合作 - hezuo), etc. (36) However, the main problem was not how to name it but lay in the very nature of this coming together and its practical applications. As noted by Scheid, (37) if it is simply a case of incorporating into Chinese medicine the scientific discoveries and technological processes that have accompanied the recent development of Western medicine, there is no real fundamental problem, and the principle has already been largely achieved: biological analyses, medical imagery, and other attributes of contemporary medical practice are already in widespread use on a daily basis by practitioners of Chinese medicine. Similarly, integrating Western medicines into Chinese medicine treatments and vice versa is also a very common practice. The real problem lies in how to merge two medical systems into a single coherent system if they do not have the same conceptual constructions.

The paradigms upon which biomedicine rests are based on a representation of the human being that is, by and large, influenced by the philosophy of Mechanism, which grew in influence from the Renaissance period and has led to man being seen as a machine about which anatomical knowledge is essential. While the Chinese do not deny the structural reality of the body, they do not accord it such a determining influence. The Western vision gives rise to learning by dissection and research based on animal experiments, whereas Chinese medicine does not, in principle, consider as self-evident the fact that a right knowledge of the living can be deduced from observations made on dead bodies. All the same, this has not stopped the growth of acupuncture research in China involving the insertion of needles into groups of rats (at points that correspond to maps that have been drawn up ad hoc, because there is no therapeutic tradition concerning this animal in China). I have often asked these researchers why they have constructed such protocols, and the answer is often the same: Chinese medicine has to be subjected to a methodology constructed by and for Western medicine in order for it to gain recognition and be accepted for publication in well-regarded biomedical reviews. Subjecting Chinese medicine to such absurd constraints compromises it and has two regrettable consequences: it loses its identity, and it does nothing to encourage research to find alternative methodologies that might be compatible with its basic foundations. Conceptual differences are therefore part of the reason for the difficulty the two medical systems have communicating with one another, especially because Western medicine positions itself as the dominant paradigm and is little inclined to accept the otherness of foreign knowledge, at the very most contemplating the integration of exotic tech- niques or substances into its own corpus, thus uprooting them from their context. Finally, there is a paradox to confront: with regard to Chinese medicine, Western medicine has a tendency to assume that its own treatments take pride of place and that those of the other medical system can do no more than fill any gaps that remain or play a complementary role, manage undesirable effects, or treat peripheral symptoms. Yet Chinese medicine is based upon a holistic vision of the human being within its environment, and has a differential diagnostic system that takes into account a much higher number of signs and symptoms, both somatic and psychic, which are neglected by biomedicine, and as a result of which it has a much more complex nosography. In a given group of patients that Western medicine might consider to be suffering from the same illness and categorise under the same therapeutic protocol, Chinese medicine would discern a certain number of distinct syndromes justifying completely different treatments. From a purely conceptual point of view, Chinese medicine is therefore better prepared to look after the patient as a whole, and especially as far as his individuality is concerned. If we accept that it is the patient rather than the medical routine that should define the treatment, Chinese medicine inevitably takes the dominant position. Besides, for the reasons set out above, Chinese medicine proves effective in the treatment of a great many complex, chronic, and recurring pathologies for which Western medicine only offers symptomatic or palliative treatment. Conversely, it is less impressive in emergency situations, in certain procedures that require technical skill and precision, and generally, when it comes to treatments intended to produce a precise and isolated physiological effect, all of which are areas in which Western medicine excels. Finally, it should not be ignored that most practitioners of Western medicine know absolutely nothing about Chinese medicine, while practitioners of Chinese medicine cannot afford to ignore Western medicine, given that they live in a world dominated by it. This is most probably one of the reasons for which the combination of Chinese medicine and Western medicine, as an official discipline, is mainly taught and practised in faculties and hospitals of Chinese medicine, and not in institutions of Western medicine.

The result of all this is that the consequences of the confrontation with Western medicine, which could have been an incredible opportunity for the two systems to evolve, are not seen as particularly successful, and are even considered disastrous by many researchers. For some, the change that has taken place in the teaching and practice of Chinese medicine could have a terrible impact on the survival of the discipline. This is the opinion of Manfred Porkert, for example, who has suggested it is in danger of totally disappearing (total eclipse), (38) and that if this were to come to pass, part of the responsibility would lie with the West. ${ }^{(39)}$ Around the same time, Paul Unschuld wrote that the roots of the process went back to a far more ancient time but that it was finalised by the People's Republic of China:

Traditional Chinese medicine in China exists no longer as an independent healing system with its own ideas and practices. The loss of

34. Dominique Hoizey, Histoire de la médecine chinoise, Paris, Payot, 1988, p. 215

35. The work of Chen and Read on ephedrine had an international impact.

36. Kim Taylor, Chinese Medicine in Early Communist China, 1945-1963: A medicine in Revolution, London, Routledge Curzon, 2005, p. 137.

37. Volker Scheid, Chinese Medicine in Contemporary China, op. cit., p. 83.

38. Manfred Porkert, Chinese Medicine Debased, Essays on Methodology, Dinkelscherben, Phainon Editions \& Media $\mathrm{GmbH}, 1998$.

39. Manfred Porkert cites three main factors, two of which have their roots in the West. See the article by Pierre-Henry de Bruyn and Evelyne Micollier in this special issue. 
the not only conceptual but also diagnostic and therapeutic independence is the result of a policy of the People's Republic of China geared to this end. It is also, however, the result of a long historical process, whose causes were present long before encounters with the West. ${ }^{(40)}$

\section{The reception and adaptation of Chinese medicine in the West}

It is clear that ever since Chinese medicine spread to the West, the issues surrounding its preservation are also linked to the way in which it is taught and practised outside China. Various aspects of Chinese medicine have reached Europe over the course of more than three centuries, initially introduced by the Jesuits and a few doctors in the Dutch West India Company, and later, from the middle of the nineteenth century, by diplomats working in China, in particular Georges Soulié de Morant, who more precisely introduced acupuncture to France at the beginning of the twentieth century. However, the Chinese medical system has only really begun to expand in the West over the past few decades. Some 20 years ago, acupuncture was the only aspect of it that was taught. Training was organised by associations who brought doctors together, or the wider public. In France, from the end of the 1980s, courses were introduced in a few faculties of medicine, and in 1988 the country saw the approval of its first inter-university diploma (DIU) in acupuncture in the faculties of medicine in Bordeaux, Lille, Lyon, Marseille, Montpellier-Nîmes, Paris-Nord (Bobigny), and Strasbourg. ${ }^{(41)}$ In 2007, this course was changed into a state diploma in acupuncture "ability." (42) At the same time, private training continued to be given either independent of or in addition to the university course, either covering different aspects of Chinese medicine or for the purpose of reaching the wider public.

However, neither of these two categories of teaching totally fulfils the strict criteria that might be expected of such a discipline. The limitations imposed by a restricted number of teaching hours prove to be an obstacle when it comes to transmitting the most subtle aspects of the theory. As for the practice, this is often limited to one-off training courses with liberal practitioners, because there are no hospital departments specialised in Chinese medicine. The recruitment of teaching staff does not meet the criteria usually required at the higher education level. As most of the teachers do not understand the Chinese language, they can only access Western literature or translations. The theory course generally consists of fewer than 300 hours of lessons given by doctors of medicine. This therapeutic branch of Chinese medicine is actually treated as an extension of biomedical studies, but there is a major disparity between the two, because the doctoral degree for physicians involves a nine-year full-time university course (several thousand hours). This context makes it difficult to produce genuine experts within the French medical profession, despite the interest and consistent efforts by a certain number of practitioners and academics who are working to improve recognition of the Chinese medical system.

Nevertheless, many practices have opened over the years. In 1996, out of a total number of 6,756 specialist practitioners, 2,061 , or 30.5 percent of them, were registered as acupuncturists. ${ }^{(43)}$ Apart from "acupuncturists," there are a great many practitioners trained in disparate ways due to a lack of regulation in the area. (44) In theory, they risk punishment for practising medicine illegally, although in reality, convictions are rare in proportion to the large number of therapists. In any case, it would be difficult to bring proceedings against them all, unless a real witch-hunt were started, which is to ignore the fact that the practices in question would simply be forced underground rather than disappearing, given the sharply increasing public demand. It also needs to be recognised that although there are undoubtedly a few opportunists who profit from the popularity of alternative medicines, most practitioners are now organised into federations that work under a professional code of ethics and organise exams on a national scale. It should also be noted that Chinese doctors have migrated to France after receiving many years of university and hospital training, and Western doctors have followed a similar path as well.

In terms of public health, however, it remains a problem that the training of doctors who would like to practise Chinese medicine in its entirety is not better regulated. One solution, which involves only training those students who have completed their studies in biomedicine, seems unrealistic when it comes to producing genuine professionals in Chinese medicine, because the range of knowledge that needs to be acquired in the two disciplines would make it necessary to follow two very long courses, one after the other, the end result being more than 15 years of full-time training. One possible solution could be adapted from the Chinese model by creating an authentic university course that would include a certain proportion of biomedicine. ${ }^{45)}$ However, such a reform cannot be envisaged in the short term. Some countries have opted for pragmatic solutions making it possible to reconcile what is legal with the social reality. For example, in Switzerland, professional federations have been very much involved in creating a status for practitioners of Chinese medicine and setting up expert bodies that have adopted a minimal training programme in biomedicine and Chinese medicine that every candidate wishing to open a practice must have passed. They have also worked with health insurance bodies to negotiate the terms of coverage applicable to the list of approved and registered professionals, with a professional code of ethics and a list of authorised and forbidden procedures. In Italian speaking cantons, a further measure has been introduced whereby any practitioner who is specialised in Chinese medicine but is not a qualified doctor must work with a general practitioner who monitors patients at the same time. This cooperation makes it possible to avoid the real and assumed risks that are often listed as reasons to prohibit medical alternatives to biomedicine. Nor is the system only a safeguard, for it also encourages the coming together of and intellectual cooperation between the two medical systems.

While the validity of such initiatives is a subject of debate, they do at least have the merit of offering realistic changes and providing a framework for practices that do exist and can no longer be hypocritically ignored. A lack of knowledge of other medical systems actually results in prejudice that not only affects patients but also the medical profession and research. In the area of cancer treatment alone, nearly half (48 percent) of cancer patients treated with chemotherapy and radiotherapy also turn to other medicines, yet 75 percent of them do not tell their doctor this is the case. These figures

40. Paul U. Unschuld, Chinese Medicine, Brookline, Paradigm Publications, 1998, p. 83.

41. I. Robard, "Situation de la médecine chinoise en France," Aesculape, no. 20, 1999, p. 5.

42. "Ability" here refers to a state diploma recognising specific training that is additional to the doctoral degree for physicians.

43. Bloc-notes statistique CNAM, no. 83, September 1997, p. 10.

44. According to Tong Zhilin, president of the Pan-European Federation of Organisation of Traditional Medicine, there are more than 30,000 Chinese medicine practices in Europe. Most specialise in acupuncture therapies. Practitioners of Chinese medicine in these practices carry out more than 5,000,000 consultations annually. More than 200 institutes teach Chinese medicine in Europe, and they produce more than 3,000 new practitioners annually (International Senior Forum of Traditional Chinese Medicines and Botanical products, Hangzhou, 18-22 October 2001).

45. For further detail on this idea, see Éric Marié, Précis de médecine chinoise, op. cit., pp. 25-31 
come from an American source from a study of 487 patients, ${ }^{(46)}$ in which the results of other studies that were published in Bulletin du cancer in 2003 and Annals of Oncology in 2005 were edited and multiplied. In France in the 1980s, an initial series of surveys had already pointed in this direction. ${ }^{(47)}$ The OMS report Stratégie pour la médecine traditionnelle pour 2002-2005 (Strategy for traditional medicine for 2002-2005) (48) openly asks about the existence and integration of "other medical systems" in national health systems. Also, in its chapter covering "Soins" (49) (Treatments) to ask and inform about, France's "Plan Cancer" of 2003-2007, which positions the patient at the centre of its approach, encourages such a strategy for therapeutic and anthropological reasons, in order to "improve the organisation of treatments around patients in a very proactive manner, making the system transparent, coordinating the treatment facilities, giving equal access to information and therapeutic innovations and covering the costs in a comprehensive, personalised manner."

The problem raised about transparency not only affects the professional code of ethics; it also has serious consequences on therapeutic research, which is hugely tainted by a wide margin of uncertainty. How is it possible to tell what can be ascribed to the patient's biomedical treatment if he or she is, at the same time but unbeknownst to his or her oncologist, receiving another treatment that might just as easily be maximising the potential or inhibiting the effects of the "officially" administered one? This same complaint applies to all of the research carried out over recent decades. It was as a consequence of this observation that France's Institut national du Cancer launched a call for projects. A three-year study was set up to explore the place of Chinese medicine in France and in Chine. ${ }^{(50)}$ Over the course of this research, I had the opportunity to question patients and doctors in the hospitals of several Chinese cities. It is interesting to note that nearly all of the patients told me they used Chinese medicine alongside chemotherapy or radiotherapy, including those who were being treated in hospitals of Western medicine that did not have a Chinese medicine department (they consulted external practitioners). When I asked the head of the oncology department in a large hospital in Beijing about such dual treatments, he told me that fewer than 10 percent of the patients adopted such a strategy, even though every single patient I had met in his own department had admitted to me that they regularly used the Chinese pharmacopoeia.

During the years I have spent studying, practising, and teaching Chinese medicine, I have been able to think about measures that would make it possible to change this kind of obscurantism and allow this discipline to be explored. First and foremost, I think it is essential to inform the medical profession and the scientific community about its reality and the issues at stake. Indeed, I have on numerous occasions observed how most of the resistance Chinese medicine meets are based on ignorance and prejudice. Whenever discussions have taken place, in a context free of any controversy, all that has been required to change people's understanding is a bit of information, and the biggest problem has always been to arouse the interest necessary for such encounters in the first place. It would be extremely helpful if health professionals and students alike could have access to information about the other medical systems, even if for only a few hours.

In the West, Chinese medicine is mainly associated with acupuncture, even though this is just one of its therapeutic branches. In China, acupuncture accounts for only 10 to 15 percent of medical practice, and is far behind pharmacopoeia, the clinical applications of which are more numerous and easier to test scientifically. Other therapies also need to be taken into account (massage, dietetics, etc.). Although these therapies are now taught in most private schools, they are not offered by any university departments. In 2007, when the Franco-Chinese cooperation programme was drawn up, ${ }^{(51)}$ the opening of a series of postgraduate degrees helped partially fill this gap. ${ }^{\left({ }^{2} 2\right)}$ They are attended by health professionals as well as students and researchers with backgrounds in different areas, in a multidisciplinary approach. This initiative marks a step forward in the study and transmission of Chinese medicine in France.

The role of universities and research institutions is essential in order to improve knowledge of Chinese medicine. The problem is that today, most researchers with an interest in the area do their work through the prism of another discipline (sinology, anthropology, history, economics, etc.), as part of an often isolated approach. The importance of the discipline is reason enough to create at least one research centre in which Chinese medicine could be studied as it actually is, without excluding the possibility of a collaboration with specialists in biomedicine and the basic or social sciences, as well as starting international collaborations with a very high number of academic institutions, not only in China but in all of the countries where the discipline has taken root. ${ }^{(53)}$

Finally, the growth of Chinese medicine presents national and European institutions and agencies with problems when it comes to assessing and regulating, as is the case, for example, with products for pharmaceutical use that come from China. The lack, in terms of competent and reliable human resources, often leads to unsuitable positions being taken up. If an expert body were to be created at the national or European level, it would be possible to look into many questions in a more dispassionate and effective manner, and to come up with well-argued responses that could be used to make valuable decisions. These specialists of Chinese medicine would also play a useful role in Franco-Chinese agreements concerning the development of research.

Ever since Chinese medicine spread across the world, its transmission and practice no longer concern only China, but also all the countries where it has become established, whether as a matter of protecting its heritage or of making its contribution to public health available to people. This international responsibility means it is essential to consider the identity of medicine as a whole, its plurality, the different ways in which it has emerged in different times and places, and its ability to evolve and adapt in an ever-changing world.

\section{Translated by Will Thornely}

46. See the American study led by Dr. Neha Vapiwala of the University of Pennsylvania in Philadelphia: Neha Vapiwala (ed.), "Patient Initiation of Complementary and Alternative Medical Therapies Following Cancer Diagnosis," Cancer Journal, vol.12, no. 6, 2006, pp. 467-474 (communication presented to the Annual ASCO meeting in 2005, Orlando, FL).

47. SOFRES survey of December 1985 and Report of February 1986 titled "Les médecines différentes, un défi ?" by the French Ministre des Affaires sociales et de la Solidarité nationale (Ministry of Social Affairs and National Solidarity) and the Secrétaire d'État chargé de la santé (Secretary of State for Health)

48. See http://archives.who.int/tbs/trm/s2298f.pdf (consulted on 24 November 2011).

49. Measures 29, 39, 42, 43, 46 of "Plan Cancer."

50. Éric Marié, Olivier Martin, Patrick Triadou, "Place de la médecine chinoise en France dans l'offre et la demande de soin en cancérologie," final report submitted in 2010.

51. Three programmes were drawn up, respectively twinning the cities of Montpellier and Chengdu, the faculty of medicine of the former and the faculty of Chinese medicine of the latter, and the university hospitals of the two cities.

52. At present, three diplomas are on offer, and additional ones are being planned. They cover the areas of Chinese medical theory, diagnostics, pharmacopoeia, massage, and qigong.

53. According to the World Health Organisation, 62.5 percent of the countries in the Western Pacific region alone have developed university courses in traditional medicine, and there are national research institutes in 69 percent of them (World Health Organisation, Regional Office of the Western Pacific, Regional committee, 52nd session, Brunei, Darussalam, 10-14 September 2001, p. 13). 